\title{
Influence of formation heterogeneity on foam flooding performance using 2D and 3D models: an experimental study
}

\author{
Ling-Zhi Hu ${ }^{1,3} \cdot$ Lin Sun ${ }^{1} \cdot$ Jin-Zhou Zhao ${ }^{1} \cdot$ Peng Wei $^{2} \cdot$ Wan-Fen Pu ${ }^{1}$
}

Received: 26 April 2019 / Published online: 26 December 2019

(c) The Author(s) 2019

\begin{abstract}
The formation heterogeneity is considered as one of the major factors limiting the application of foam flooding. In this paper, influences of formation properties, such as permeability, permeability distribution, interlayer, sedimentary rhythm and 3D heterogeneity, on the mobility control capability and oil displacement efficiency of foam flooding, were systematically investigated using $2 \mathrm{D}$ homogeneous and $2 \mathrm{D} / 3 \mathrm{D}$ heterogeneous models under $120^{\circ} \mathrm{C}$ and salinity of $20 \times 10^{4} \mathrm{mg} / \mathrm{L}$. The flow resistance of foam was promoted as the permeability increased, which thus resulted in a considerable oil recovery behavior. In the scenario of the vertical heterogeneous formations, it was observed that the permeability of the high-permeable layer was crucial to foam mobility control, and the positive rhythm appeared favorable to improve the foam flooding performance. The additional oil recovery increased to about $40 \%$. The interlayer was favorable for the increases in mobility reduction factor and oil recovery of foam flooding when the low permeability ratio was involved. For the 3D heterogeneous formations, foam could efficiently adjust the areal and vertical heterogeneity through mobility control and gravity segregation, and thus enhancing the oil recovery to $11 \%-14 \%$. The results derived from this work may provide some insight for the field test designs of foam flooding.
\end{abstract}

Keywords Foam flooding $\cdot$ Permeability ratio $\cdot 2 \mathrm{D} / 3 \mathrm{D}$ models $\cdot$ Heterogeneity $\cdot$ Enhanced oil recovery

\section{Introduction}

The technical feasibility of foam flooding for enhanced oil recovery (EOR) has been approved previously (Wei et al. 2018; Zhang et al. 2010). It was recognized that the high

Edited by Yan-Hua Sun

Lin Sun

slswpu@163.com

$\triangle$ Jin-Zhou Zhao

Zhaojz62@163.com

$\triangle$ Peng Wei

shibadin@qq.com

1 State Key Laboratory of Oil and Gas Reservoir Geology and Exploitation, Southwest Petroleum University, Chengdu 610500, Sichuan, China

2 MOE Key Laboratory of Oil and Gas Fine Chemicals, School of Chemistry and Chemical Engineering, Xinjiang University, Urumchi 830046, Xinjiang, China

3 Yumen Oilfield of Chinese National Petroleum Corp, Yumen 735211, Gansu, China flow resistance created by foam in high-permeability zones could promote fluid diversion to the previously unswept zones, and the gravity difference appeared in the presence of foam could help to sweep the upper part of reservoirs (Ma et al. 2013; Pang et al. 2018). Meanwhile, owing to the viscoelastic liquid films, the superposed gas bubbles could squeeze and pull oil droplets out of the dead end pores (Arnold and Wit 1990; Ashoori et al. 2011). Furthermore, the foam agents, which are surfactant-based materials, help in reducing the interfacial tension between oil and water and altering rocky wettability (Kamal 2016; Kumar et al. 2008; $\mathrm{Pu}$ et al. 2016). Therefore, a foam flooding process is not only capable of improving the sweep efficiency but also able to improve the microscopic displacement efficiency, which therefore results in a significantly high oil recovery factor (Farajzadeh et al. 2009a, 2012; Shokrollahi et al. 2014).

It was well-documented that the sweep efficiency of foam flooding could be noticeably improved through screening foam agents and optimizing injected parameters (Hou et al. 2013; Li et al. 2011; Liu et al. 2014; Wang et al. 2015). In addition to the aforementioned, the physical properties of the formation also play a crucial role in foam flooding behavior. 
As some researchers claimed, the mobility reduction factor (MRF) that represents the mobility control capacity of foam in the porous media is significantly improved with the increases in core permeability and core length (Farajzadeh et al. 2009b; Wang et al. 2012; Zhao et al. 2012). In terms of heterogeneous formations, foam creates a high sweep efficiency by diverting fluids to relatively low-permeable zones (Liu et al. 2008), especially for the positive rhythm cases (Liu et al. 2010; Ma et al. 2013). Siddiqui et al. (1997) stated that fluid diversion can be enhanced by increasing the permeability ratio within a specific range. While placing an impermeable layer in the multilayer core, the crossflow and fluid diversion are both hindered in foam flooding. Although pioneering works have made great efforts to address the factors that influence the foam sweep efficiency, there are very limited studies of the impact of formation heterogeneity, which is believed to be extremely important for design of foam flooding pilot in oilfields.

Given this issue, the primary objective of this work is to systematically investigate the EOR performance of foam flooding in different types of formations, and figure out the influence of formation structure on the foam flooding efficiency. To accomplish this research objective, long sand packs, which had different permeabilities, were initially set up to examine the flow behavior of foam including mobility control and flow resistance in the subsequent waterflooding. Thereafter, 2D homogeneous/heterogeneous cores were used to study the effects of permeability, permeability distribution, interlayer and sedimentary rhythm on the foam mobility control and oil recovery. Eventually, foam flooding tests were carried out in the 3D heterogeneous models to comprehensively investigate the displacement behavior in complex heterogeneous conditions.

\section{Experimental}

\subsection{Materials}

Crude oil and formation water were kindly provided by an oilfield located in western China. The viscosity of the crude oil was about $8.5 \mathrm{mPa} \mathrm{s}$ at $120{ }^{\circ} \mathrm{C}$. The composition of formation water is given in Table $1 . \mathrm{N}_{2}$ had purity of $99.9 \%$ (Xinju Co., Ltd). The foaming agent HTS was synthesized in our laboratory, which was a mixture of glycoside surfactant and zwitterionic surfactant. Based on the Waring blender method, the foam volume and the half-life time of a $0.2 \%$ HTS solution were $580 \mathrm{~mL}$ and $185 \mathrm{~s}$ at $120{ }^{\circ} \mathrm{C}$. The interfacial tension between the $0.2 \%$ HTS solution and the crude oil was $1.5 \mathrm{mN} / \mathrm{m}$. Quartz sand was supplied by Pixian Co., Ltd (Chengdu, China). The cores used in this work were artificial cores mainly composed of quartz sand, and supplied by the Northeast Petroleum University (Daqing, China).

\subsection{Experimental apparatus and procedures}

The sand pack and 2D model tests were conducted at $20 \mathrm{MPa}$ and $120^{\circ} \mathrm{C}$. The $3 \mathrm{D}$ model tests were carried out at $5 \mathrm{MPa}$ and $120^{\circ} \mathrm{C}$. In all experiments, foam flooding was carried out by co-injecting the nitrogen and foam solution $(0.2 \%$ HTS, foam quality was 0.67$)$.

\subsubsection{Sand pack tests}

Figure 1 shows a schematic diagram of the apparatus for sand pack tests. Four pressure monitoring ports were evenly distributed along the sand pack, which was filled with quartz sand (70-140 mesh). The length and diameter of the sand packs were $100 \mathrm{~cm}$ and $2.5 \mathrm{~cm}$, respectively. The physical parameters of the sand packs are listed in Table 2.

The formation water was first injected at $1.0 \mathrm{~mL} / \mathrm{min}$ followed by foam injection. At each stage, the differential pressure $\Delta P_{\text {wi }}$ of water and $\Delta P_{\text {fi }}$ of foam at each section were recorded (Fig. 2) when four pressures changed slightly. Thereafter, the corresponding mobility reduction factor (MRF) was calculated from Eq. (1). Formation water injection was resumed at the same rate $(1.0 \mathrm{~mL} /$ min), and the dynamic differential pressure $\Delta P_{\text {swi }}$ was measured in order to obtain the residual resistance factor (RRF) from Eq. (2).

$\mathrm{MRF}=\frac{\Delta P_{\mathrm{fi}}}{\Delta P_{\mathrm{wi}}}$

Table 1 Composition of formation water

\begin{tabular}{|c|c|c|c|c|c|c|}
\hline \multirow[t]{2}{*}{ Total salinity, mg/L } & \multicolumn{3}{|c|}{ Cation concentration $C_{\text {cation }}, \mathrm{mg} / \mathrm{L}$} & \multicolumn{3}{|c|}{ Anion concentration $C_{\text {anion }}, \mathrm{mg} / \mathrm{L}$} \\
\hline & $\mathrm{K}^{+}+\mathrm{Na}^{+}$ & $\mathrm{Ca}^{2+}$ & $\mathrm{Mg}^{2+}$ & $\overline{\mathrm{Cl}^{-}}$ & $\mathrm{SO}_{4}^{2-}$ & $\mathrm{HCO}_{3}^{-}$ \\
\hline 204,672 & $67,430.31$ & $10,279.6$ & 1200.74 & $125,501.51$ & 150 & 88.17 \\
\hline
\end{tabular}




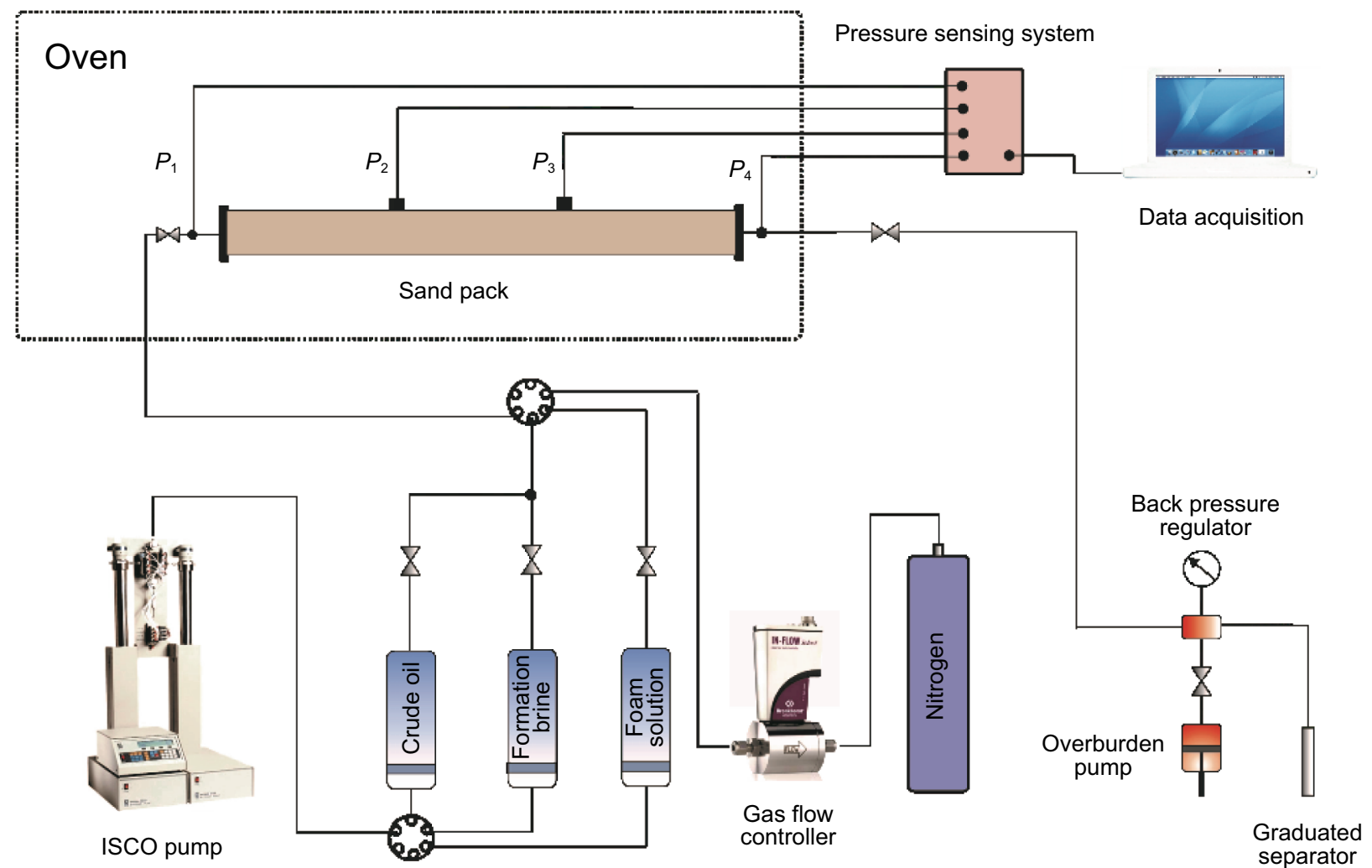

Fig. 1 Schematic diagram of the apparatus for sand pack tests

Table 2 Physical parameters of the sand packs used

\begin{tabular}{lll}
\hline Sand pack No. & Porosity, $\%$ & $\begin{array}{l}\text { Water } \\
\text { permeability, } \\
\mathrm{mD}\end{array}$ \\
\hline 1 & 27.3 & 291 \\
2 & 28.5 & 753 \\
3 & 30.6 & 1105 \\
4 & 31.8 & 1592 \\
\hline
\end{tabular}

$\Rightarrow$\begin{tabular}{|ccccccc}
$P_{1}$ & $\Delta P_{1}$ & $P_{2}$ & $\Delta P_{2}$ & $P_{3}$ & $\Delta P_{3}$ & $P_{4}$ \\
\hline & Front & & Middle & & Tail \\
\hline
\end{tabular}

Flow direction

Fig. 2 Diagram of pressure monitoring for sand pack tests. The red arrow points to the flow direction

$\mathrm{RRF}=\frac{\Delta P_{\mathrm{swi}}}{\Delta P_{\mathrm{wi}}}$
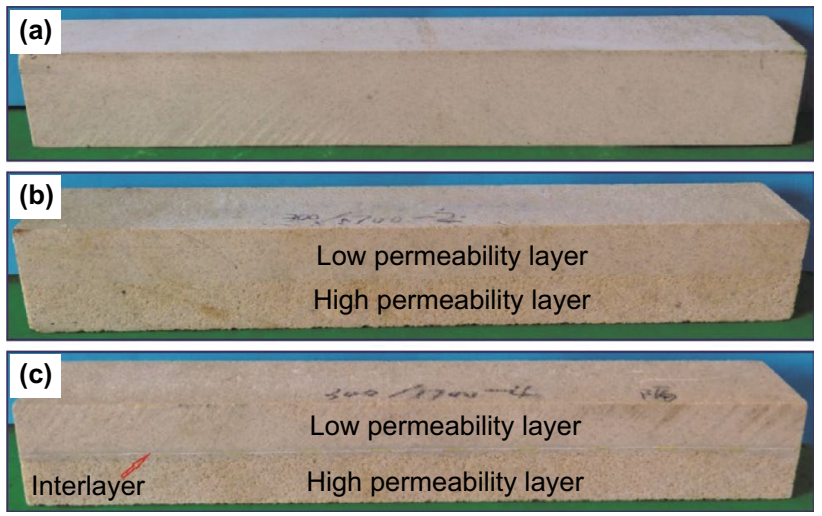

Fig. 3 Images of different cuboid cores. a Homogeneous core. b Two-layered heterogeneous core. c Two-layered heterogeneous core with an interlayer involved

\subsubsection{D model tests}

The apparatus for 2D model tests is analogous to Fig. 1 with the exception of the porous media. To simulate different permeability properties, three types of cuboid cores were prepared as shown in Fig. 3. For the multilayer core, the high permeability layer was placed at the bottom of the core holder to simulate the positive rhythm if not specified. 
Table 3 Physical parameters of the homogeneous cores for oil displacement experiments

\begin{tabular}{llllrr}
\hline Core No. & Length, $\mathrm{cm}$ & Cross-sectional area, $\mathrm{cm}^{2}$ & Porosity, $\%$ & $\begin{array}{l}\text { Average gas permeability } \\
K_{\mathrm{g}}, \mathrm{mD}\end{array}$ & $\begin{array}{l}\text { Initial oil } \\
\text { saturation, } \\
\%\end{array}$ \\
\hline 11 & 29.90 & 19.98 & 16.02 & 200 & 63.3 \\
12 & 30.01 & 20.10 & 18.17 & 300 & 71.7 \\
13 & 29.30 & 19.93 & 23.30 & 700 & 65.3 \\
14 & 29.41 & 19.78 & 28.03 & 1700 & 67.6 \\
15 & 29.72 & 20.03 & 28.76 & 2000 & 69.5 \\
\hline
\end{tabular}

Table 4 Physical parameters of the heterogeneous cores

\begin{tabular}{|c|c|c|c|c|c|c|c|c|}
\hline Experiment & Notes & Core No. & Length, $\mathrm{cm}$ & $\begin{array}{l}\text { Cross-sectional } \\
\text { area, } \mathrm{cm}^{2}\end{array}$ & Porosity, \% & $K_{\min }, \mathrm{mD}$ & $K_{\max }, \mathrm{mD}$ & $\begin{array}{l}\text { Initial oil } \\
\text { saturation, } \\
\%\end{array}$ \\
\hline \multirow[t]{5}{*}{ Mobility control } & \multirow[t]{3}{*}{ No interlayer } & 21 & 28.80 & 18.35 & 17.87 & 300 & 700 & 0 \\
\hline & & 22 & 29.03 & 18.56 & 18.33 & 700 & 1700 & 0 \\
\hline & & 23 & 29.12 & 18.30 & 18.73 & 300 & 1700 & 0 \\
\hline & \multirow[t]{2}{*}{ Interlayered } & 31 & 28.95 & 18.28 & 17.31 & 300 & 700 & 0 \\
\hline & & 32 & 28.91 & 18.73 & 17.02 & 300 & 1700 & 0 \\
\hline \multirow[t]{7}{*}{ Oil displacement } & \multirow[t]{5}{*}{ No interlayer } & 24 & 29.70 & 18.89 & 17.97 & 300 & 700 & 73.3 \\
\hline & & 25 & 29.56 & 18.92 & 17.91 & 300 & 700 & 78.3 \\
\hline & & 26 & 29.30 & 19.50 & 20.34 & 700 & 1700 & 66.7 \\
\hline & & 27 & 29.80 & 18.70 & 17.96 & 300 & 1700 & 68.9 \\
\hline & & 28 & 29.30 & 19.20 & 18.19 & 300 & 1700 & 72.8 \\
\hline & \multirow[t]{2}{*}{ Interlayered } & 33 & 28.90 & 19.02 & 15.56 & 300 & 700 & 75.0 \\
\hline & & 34 & 28.82 & 18.95 & 16.75 & 300 & 1700 & 66.3 \\
\hline
\end{tabular}

$K_{\min }$ and $K_{\max }$ are the average gas permeability of the low permeability layer and the high permeability layer, respectively

The physical properties of the cuboid cores are given in Tables 3 and 4.

In mobility control experiments, formation water was first injected until the steady state was reached; afterward, the foam was injected, during which the dynamic differential pressure $\left(\Delta P_{\mathrm{fj}}\right)$ was recorded in order to calculate MRF.

In the case of oil displacement experiments, waterflooding was first conducted until the water cut reached $98 \%$. After that, 0.5 pore volume (PV) foam was injected followed by waterflooding. The injection rate of $1.2 \mathrm{~mL} / \mathrm{min}$ was used in the 2D model tests.

\subsubsection{D model tests}

A schematic diagram of the apparatus for 3D model tests is shown in Fig. 4. The 3D model had dimensions of $14.4 \mathrm{~cm} \times 14.4 \mathrm{~cm} \times 10.2 \mathrm{~cm}$ (length, width, and height) and was equipped with six valves. Valves 1 and 2 were regarded as an injection well and a production well, respectively. Valves $a, b, c$ and $d$ were the spare switches used to operate the water and oil saturation process. Three types of sands (i.e, 70-140 mesh, fine; 40-70 mesh, medium; $20-40$ mesh, rough) were used to prepare the 3D models with the three layers for the same thickness, which are particularly shown in Fig. 5 and Table 5.

The procedures of oil displacement experiments conducted on the 3D model were similar to that of the 2D model tests. The only difference was that the injection rate was $4.0 \mathrm{~mL} / \mathrm{min}$. Moreover, images of the three sand layers were captured with a high-resolution camera, and then software ImageJ was used to analyze the residual oil distribution.

\section{Results and discussion}

\subsection{Mobility control behavior in sand packs of different permeabilities}

\subsubsection{Mobility control}

It was known that dynamic equilibrium process between generation and destruction usually occurs during foam 


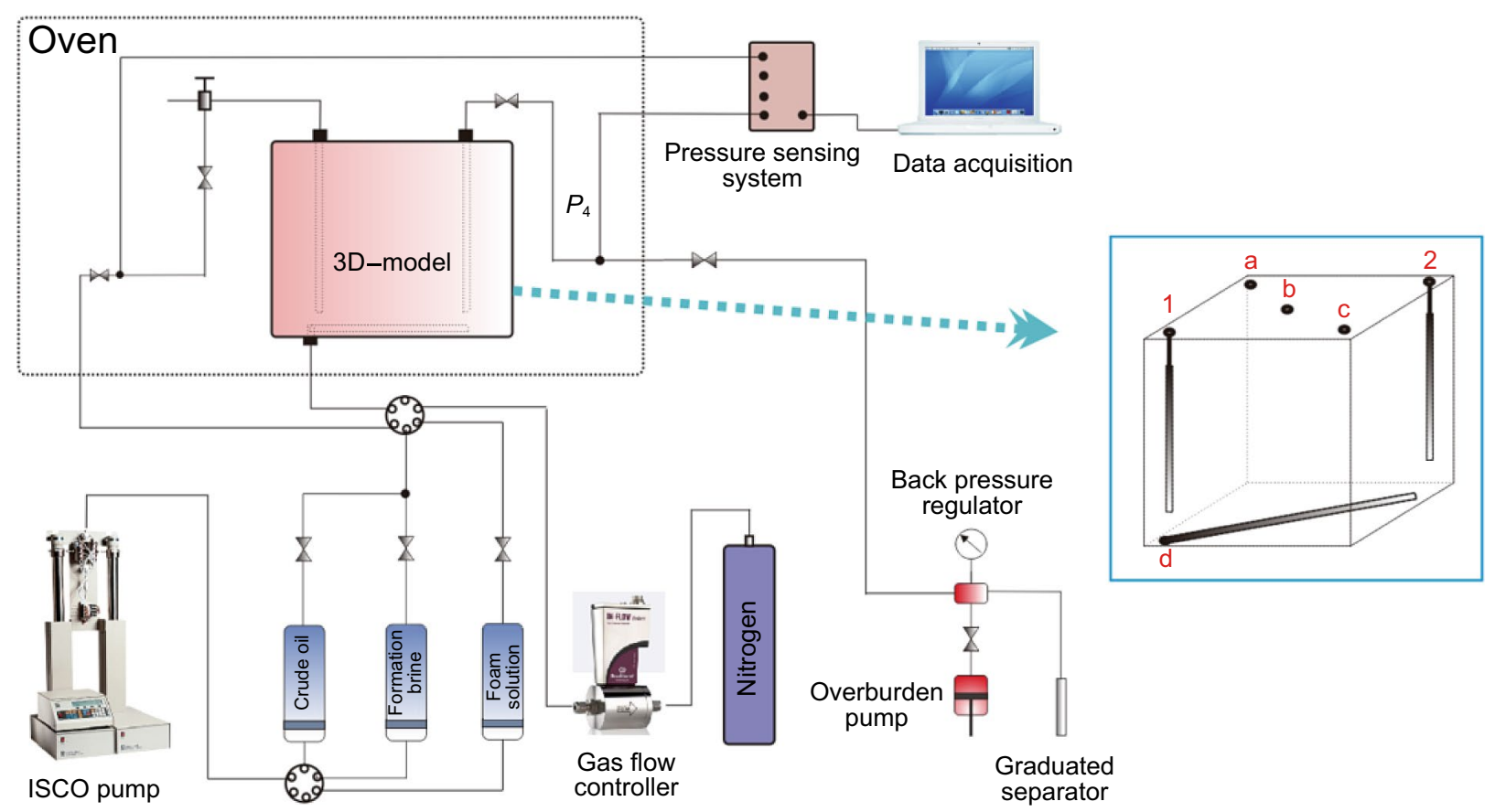

Fig. 4 Schematic diagram of the apparatus for 3D model tests

propagating in porous media (Blázquez et al. 2016). Hence, if the foam generation exceeds rupture, MRF would increase and thus strengthen the mobility control capability and vice versa (Almajid and Kovscek 2016). The rates of foam generation and destruction vary with permeability, which would alter the mobility control characteristics during foam flooding. As shown in Fig. 6, when the water permeability of the sand pack was less than or equal to 1105 $\mathrm{mD}\left(K_{\mathrm{w}} \leq 1105 \mathrm{mD}\right)$, the MRF progressively reduced from the front to the tail. Moreover, as the sand pack permeability increased, the position where the largest value of MRF occurred shifted from the front to the tail, which revealed that the effective distance of foam mobility control was extended. Regarding the same part of different permeability sand packs, the high permeability resulted in the large MRF. Nevertheless, when the permeability was increased to $1592 \mathrm{mD}$, the MRF in the front turned out to be smaller than that of the $753-\mathrm{mD}$ one; meanwhile, the generated MRF gradually increased from the front to the tail. With the exception of the MRF in the front, the MRF in the other parts was larger than all the evaluated sand packs. This interesting result could be attributed to the shear forces and entrance effects in the porous media (Ashoori et al. 2011). The weaker shear and more obvious entrance effect were found at a higher permeability porous medium (Parlar et al. 1995). As a result, the weak foam texture was produced in the front of the sand pack $(1592 \mathrm{mD})$, and the low shear rate led to high apparent viscosity of foam, which benefited foam mobility control in the other parts.

\subsubsection{Flow resistance in the subsequent waterflooding}

The RRF produced during water injection can illustrate the flow resistance in the subsequent waterflooding in the presence of foam. As shown in Fig. 7, with an increase in permeability, the shape of RFF curves was significantly changed. This result is believed to be associated with foam destruction and fluid diversion. As a result of the augmented flow resistance in large pores, the subsequent water could sweep both the large and small pores. The water in the large pores accelerated foam destruction and thus caused the RRF to reduce. On the contrary, the water diverted to small pores would increase the flow differential pressure and also RRF, especially in high permeability sand packs with strong mobility control potential. Consequently, when the permeability was high enough, the RRF would be promoted substantially at the early stage of water injection. Furthermore, the equilibrium $\mathrm{RRF}$, the ratio of the maximum RFF to the initial RFF and also the corresponding water-injected volume were all directly proportional to permeability. The data demonstrated that the effective time of foam mobility control prolonged with permeability.

\subsection{Foam flooding performance in 2D homogeneous models}

Five homogeneous cores with average gas permeability $K_{\mathrm{g}}$ of 200-2000 mD were used to study the effect of permeability on the performance of foam in EOR. The experimental 
(a)

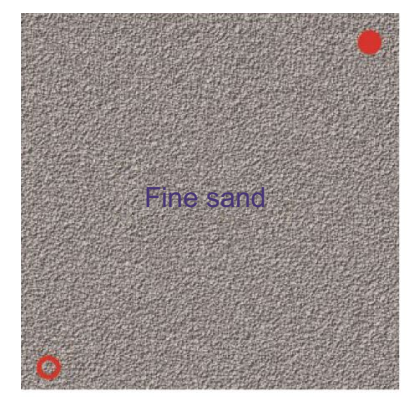

(b)

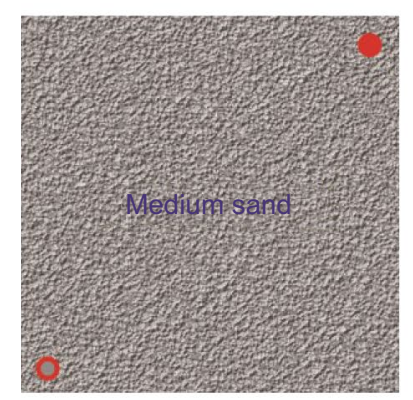

(c)

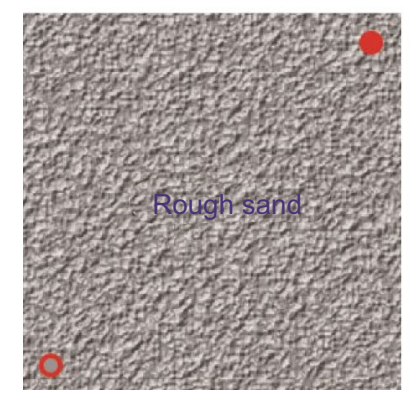

Model B
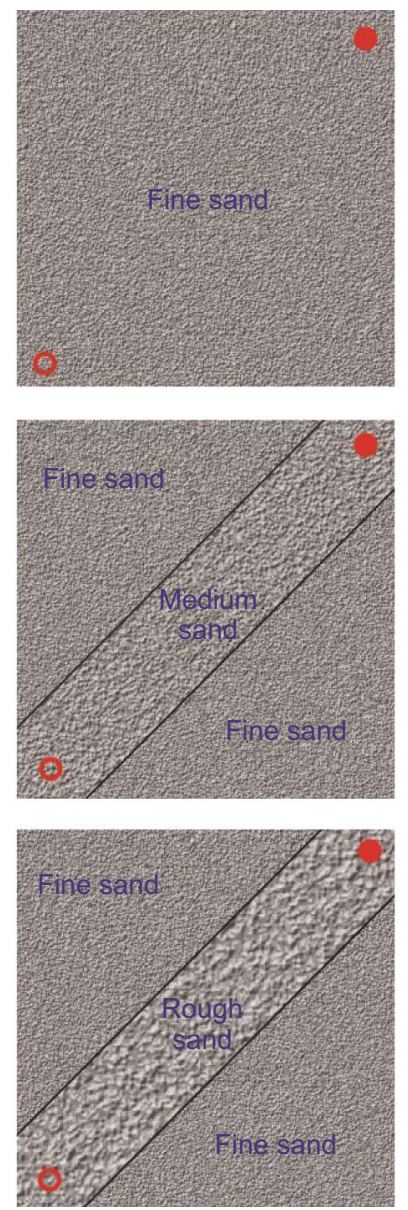

Model C
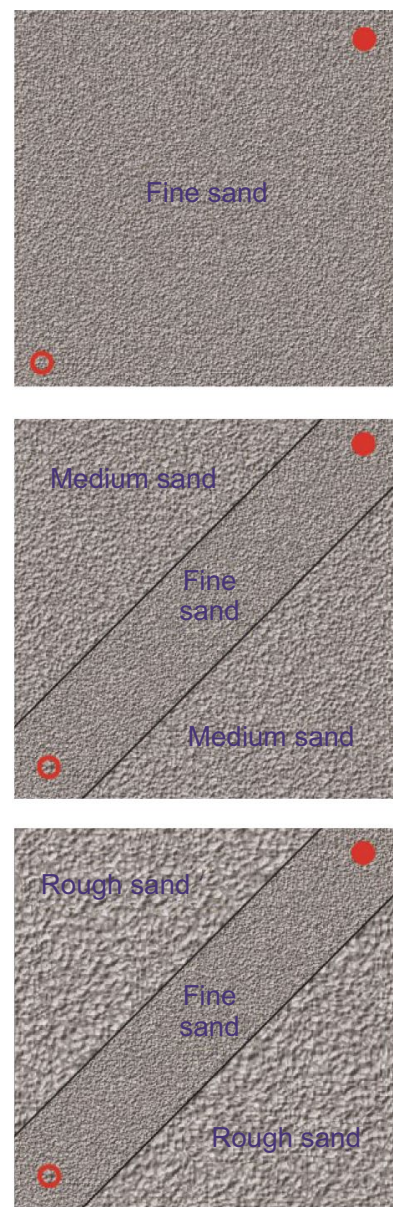

Fig. 5 Patterns of sand packing in the 3D models (i.e., Model A, Model B, Model C). a Top layer, b middle layer and $\mathbf{c}$ bottom layer of the model. Open circle: injection well and closed circle: production well

Table 5 Permeability properties of the 3D models

\begin{tabular}{|c|c|c|}
\hline Model No. & Areal & Vertical \\
\hline Model A & Homogeneity & Positive rhythm \\
\hline Model B & $\begin{array}{l}\text { Wells are in high perme- } \\
\text { ability zone of the middle } \\
\text { and bottom layers }\end{array}$ & $\begin{array}{l}\text { Wells are in positive } \\
\text { rhythm zone, while } \\
\text { wing areas are homo- } \\
\text { geneous. }\end{array}$ \\
\hline Model C & $\begin{array}{l}\text { Wells are in low perme- } \\
\text { ability zone of the middle } \\
\text { and bottom layers }\end{array}$ & $\begin{array}{l}\text { Wells are in homoge- } \\
\text { neous zone, while } \\
\text { wing areas are posi- } \\
\text { tive rhythm }\end{array}$ \\
\hline
\end{tabular}

results are given in Table 6 , and the production dynamics are shown in Fig. 8.

As given in Table 6, with an increase in permeability, the waterflooding recovery and the additional oil recovery of foam flooding and subsequent waterflooding were both enhanced. It was also observed that when the permeability $K_{\mathrm{g}} \geq 700 \mathrm{mD}$, the water cut dropped precipitously to

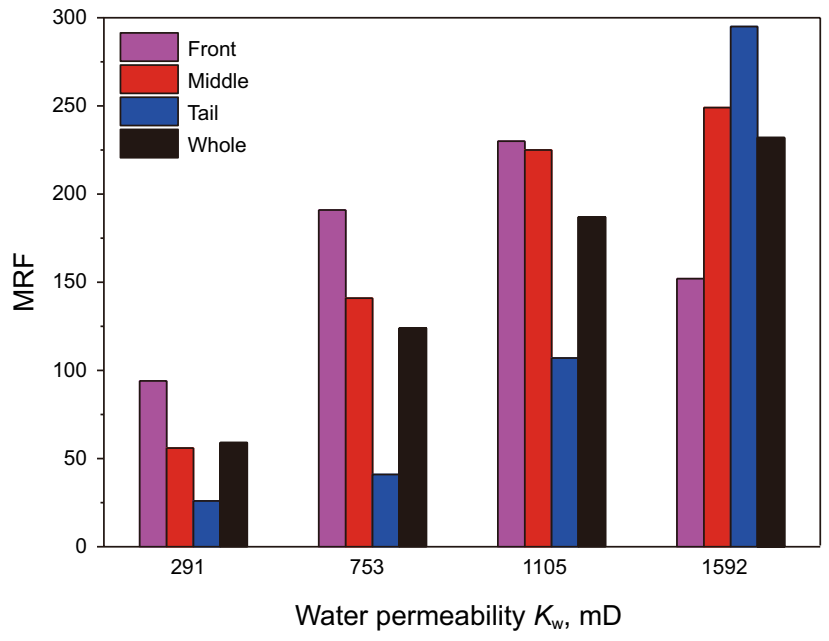

Fig. 6 MRF in different parts of sand packs at the steady state 

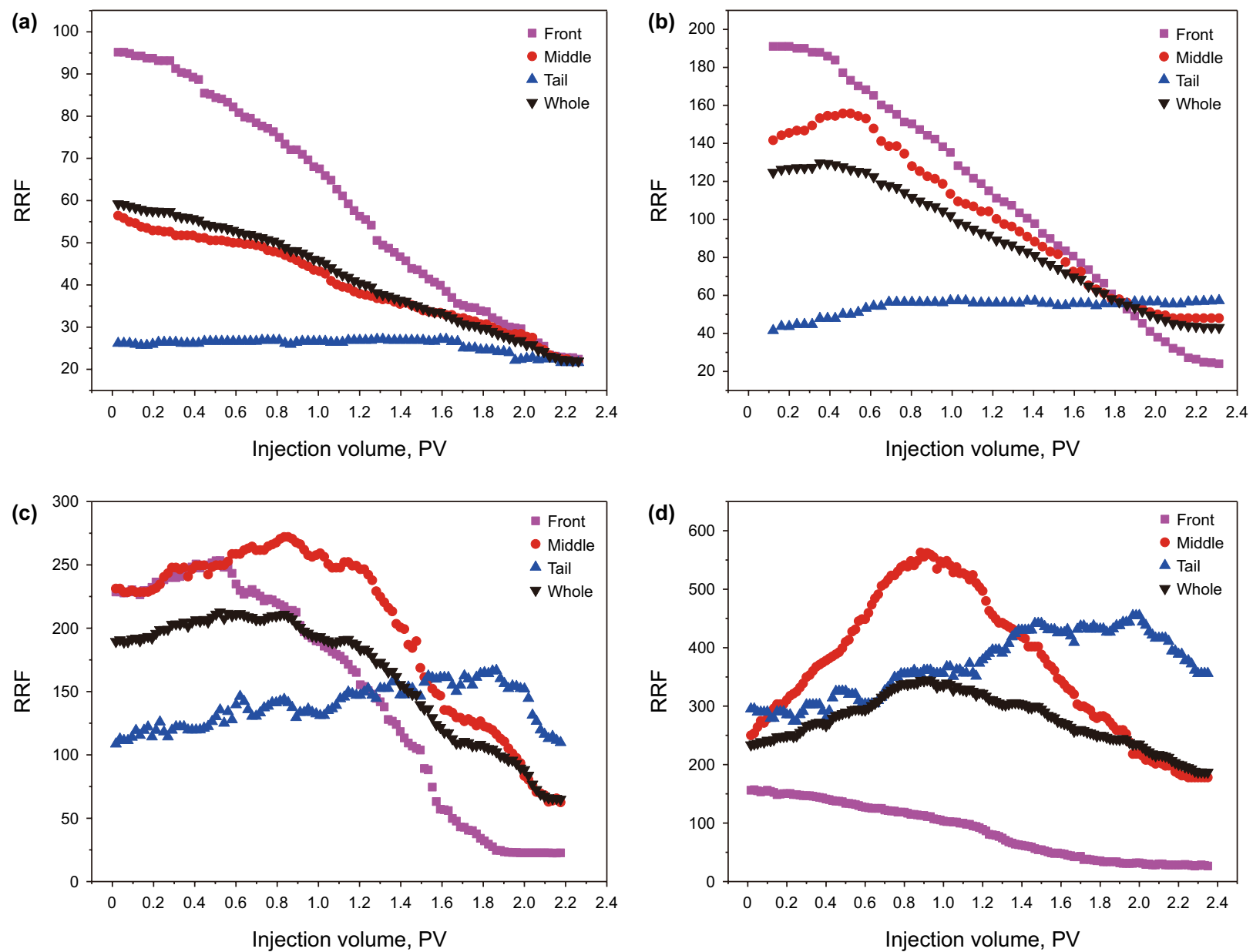

Fig. 7 Residual resistance factor (RRF) in different permeability sand packs as a function of injection volume. a $295 \mathrm{mD}$. b $753 \mathrm{mD}$. c 1105 mD. d $1592 \mathrm{mD}$

Table 6 Summary of oil displacement tests

\begin{tabular}{llllccc}
\hline Core No. & $\begin{array}{l}\text { Gas permeability } \\
K_{\mathrm{g}}, \mathrm{mD}\end{array}$ & $\begin{array}{l}\text { Waterflooding } \\
\text { recovery, } \%\end{array}$ & $\begin{array}{l}\text { Foam flooding } \\
\text { recovery, } \%\end{array}$ & $\begin{array}{l}\text { Subsequent waterflood- } \\
\text { ing recovery, } \%\end{array}$ & $\begin{array}{l}\text { Additional oil } \\
\text { recovery, } \%\end{array}$ & $\begin{array}{l}\text { Total recovery, } \% \\
11\end{array}$ \\
\hline 200 & 28.33 & 8.79 & 8.39 & 17.18 & 45.51 \\
12 & 300 & 28.96 & 11.81 & 12.88 & 24.69 & 53.65 \\
13 & 700 & 40.77 & 16.09 & 16.30 & 32.39 & 75.16 \\
14 & 1700 & 43.33 & 17.75 & 16.62 & 34.38 & 77.71 \\
15 & 2000 & 45.47 & 21.98 & 13.43 & 35.41 & 80.88 \\
\hline
\end{tabular}

$47 \%-63 \%$ due to foam injection, and remained at a low level for quite a long duration of time (Fig. 8). This result can be interpreted as follows: (1) For a higher permeability core, the oil recovery was in a larger enhancement as foam flooding was conducted, and the smaller-sized pores in the oil-bearing zones were supposed to be substantially swept resulting from the mobility control and water flow resistance in the presence of foam. (2) The stable foam in the high permeability cores could improve the oil displacement efficiency (Sun et al. 2014). Moreover, the low residual oil saturation in the high-permeability cores after waterflooding was in favor of mitigating the de-foaming effect of oil to foam, which has been previously verified (Blázquez et al. 2016; Sun et al.2014). 

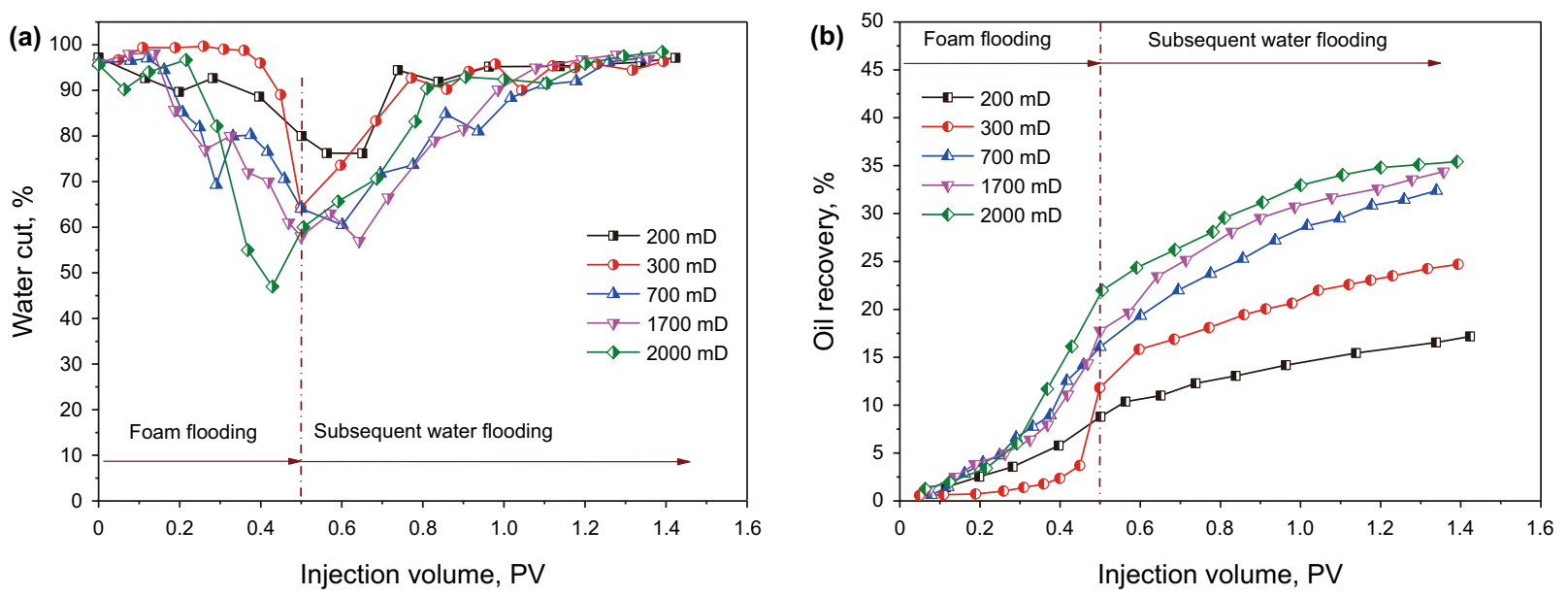

Fig. 8 a Water cut and $\mathbf{b}$ oil recovery as a function of injection volume for 2D models of different permeabilities

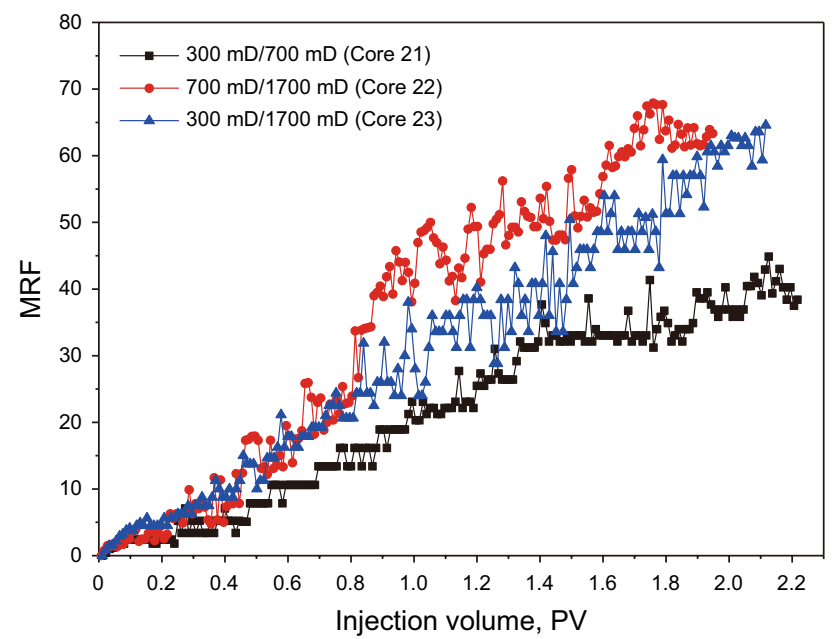

Fig. $9 \mathrm{MRF}$ as a function of injection volume for $2 \mathrm{D}$ heterogeneous models of different permeability distributions

\subsection{Foam flooding performance in 2D heterogeneous models}

In some research, several independent cores were parallelized to simulate heterogeneous formations in the laboratory (Shamekhi 2013; Xiao et al. 2014; Vernáez et al. 2016). However, the system without capillary communication can hardly represent the state of the real flow. Therefore, in our study, two types of heterogeneous cores, i.e., two-layered heterogeneous cores and two-layered heterogeneous cores with interlayer involved were assembled.

\subsubsection{Effect of permeability distribution}

The heterogeneous cores were set up to examine the effect of permeability distribution on foam flooding behavior.

Figure 9 plots the MRF as a function of the volume of foam injected. The data indicated that the maximum permeability $K_{\max }$ was the dominant factor for foam mobility control in the heterogeneous cores, while the permeability ratio only determined the increasing rate of MRF. At the very early stage of foam injection, foam was prone to be generated and propagated in the high permeability layer (Thompson and Gdanski 1993). Therefore, the increasing rate of MRF was almost identical in Cores 22 and 23, which had the same $K_{\max }$. Whereas once the foam was diverted to the low permeability layer, a much higher increasing rate of MRF was found in Core 22 which had a higher $K_{\text {min }}$. After a sufficient volume of foam had been injected, the high permeability layer would be saturated with strong foam, which subsequently formed a considerable MRF that represented the entire core. The phenomena could be understood by the

Table 7 Oil recovery for different permeability distributions

\begin{tabular}{llllllll}
\hline Core No. & $\begin{array}{l}\text { Permeability } \\
\text { ratio }\end{array}$ & $K_{\max }, \mathrm{mD}$ & $\begin{array}{l}\text { Waterflooding } \\
\text { recovery, } \%\end{array}$ & $\begin{array}{l}\text { Foam flooding } \\
\text { recovery, } \%\end{array}$ & $\begin{array}{l}\text { Subsequent water } \\
\text { recovery, } \%\end{array}$ & $\begin{array}{l}\text { Additional oil } \\
\text { recovery, } \%\end{array}$ & $\begin{array}{l}\text { Total recovery, } \% \\
24\end{array}$ \\
\hline 2.3 & 700 & 32.47 & 11.57 & 16.35 & 27.92 & 60.39 \\
26 & 2.4 & 1700 & 34.26 & 16.13 & 19.06 & 35.19 & 69.45 \\
27 & 5.7 & 1700 & 30.07 & 22.60 & 17.67 & 40.27 & 70.34 \\
\hline
\end{tabular}



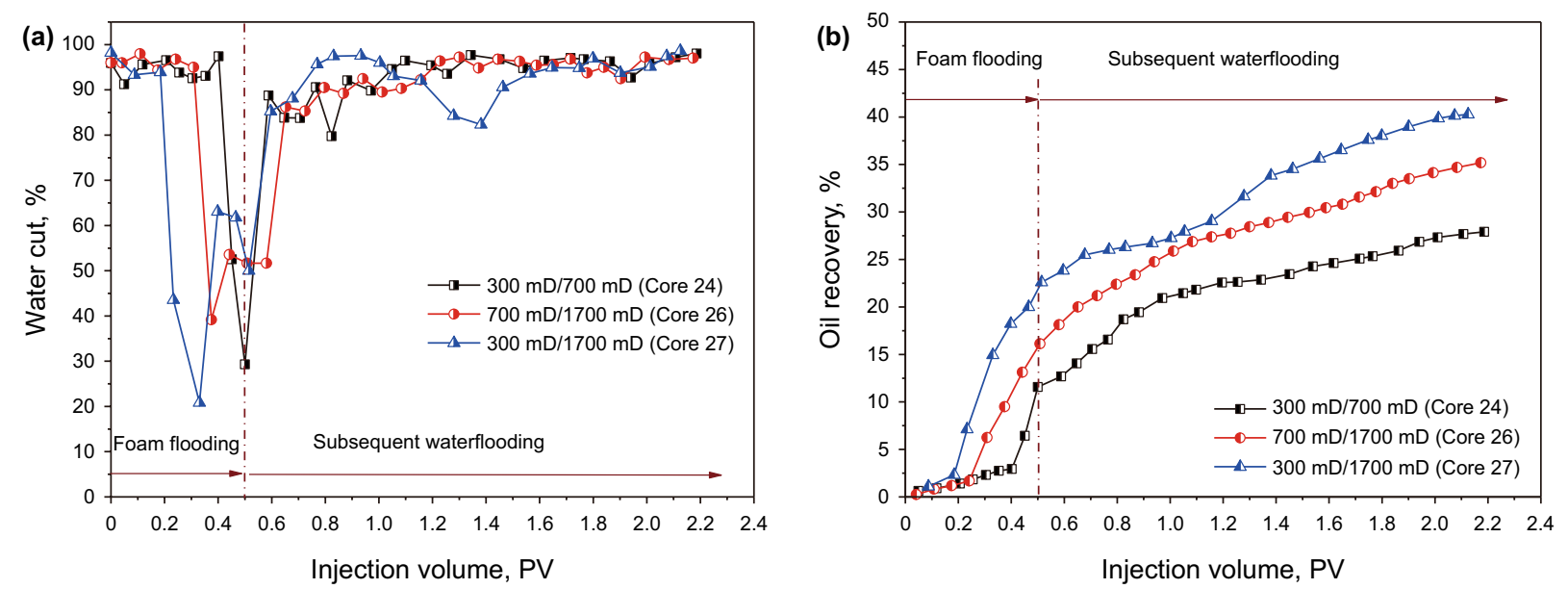

Fig. 10 a Water cut and $\mathbf{b}$ oil recovery as a function of injection volume for $2 \mathrm{D}$ heterogeneous models of different permeability distributions

same equilibrium MRFs of Cores 22 and 23, and the discrepant equilibrium MRFs of Cores 21 and 22.

The production dynamics in the heterogeneous cores with different permeability distributions are shown in Table 7 and Fig. 10. It can be seen that both the $K_{\max }$ and permeability ratio significantly influenced the oil recovery of foam flooding. At the given permeability ratio (Cores 24 and 26), the additional oil recovery increased with an increase in $K_{\max }$. Similarly, Pu et al. (2017) found that the oil recovery enhanced by foam increased with the permeability as foam flooding was conducted in the heterogeneous cores. Moreover, the water cut quickly declined to the lowest level and remained low for a relatively long production time. With an increase in $K_{\max }$, the foam could not only displace the oil from the high permeability layer, but also form a stable front for the subsequent waterflooding. At the given $K_{\max }$ (Cores 26 and 27), similar tendencies of oil recovery and water cut were also observed with an increase in the permeability ratio. The low waterflooding recovery of Core 27 provided a high potentiality of oil recovery for the foam flooding. In addition, a comparison of Figs. 8 and 10 verified that foam flooding would be more efficient for heterogeneous reservoirs than that for homogenous reservoirs, which was reported by Liu et al. (2008).

\subsubsection{Effect of interlayer}

The effect of interlayer on foam flooding behavior was investigated in heterogeneous cores with the same permeability ratio. The details of foam flooding are listed in Table 8.

As shown in Fig. 11, the effect of interlayer varied with permeability ratio mostly embodied two aspects: the larger MRF was generated in the case of interlayered cores with the low permeability ratio (2.3-2.4); On the contrary, the
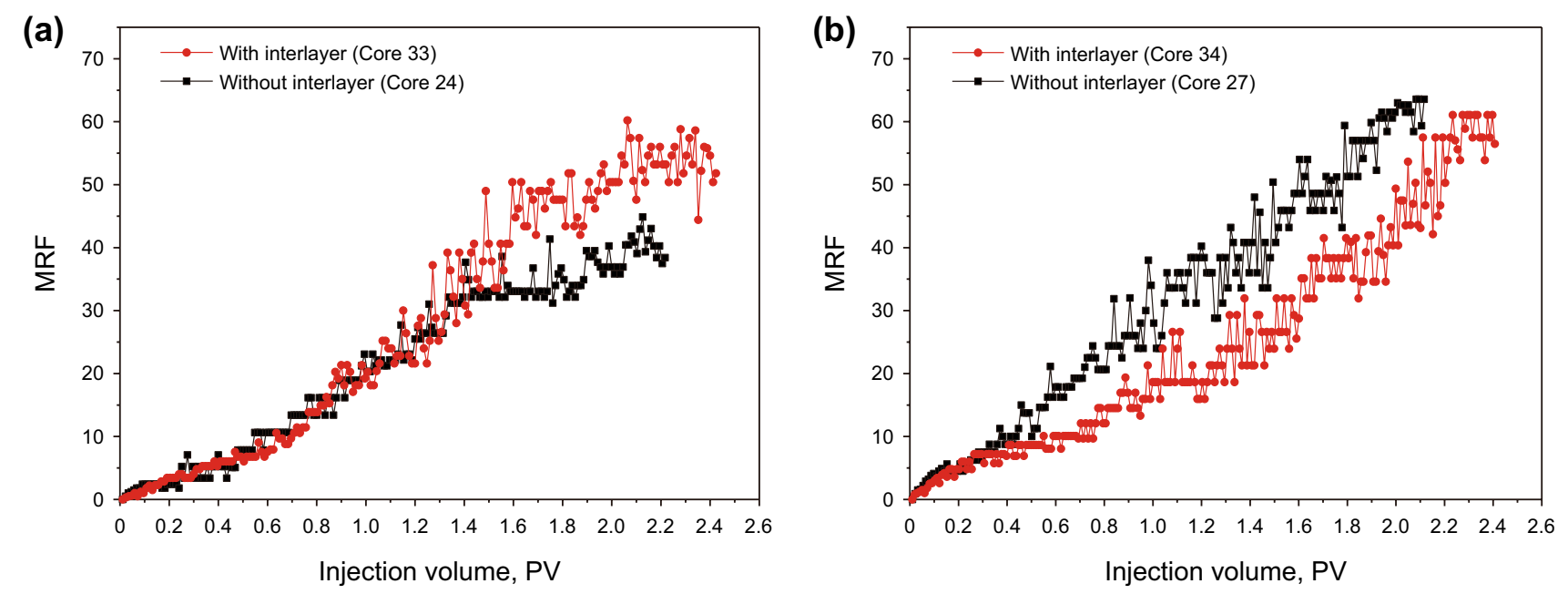

Fig. $11 \mathrm{MRF}$ as a function of injection volume in 2D heterogeneous models with or without interlayer. a Heterogeneous cores of a low permeability ratio $(300 \mathrm{mD} / 700 \mathrm{mD})$. b Heterogeneous cores of a high permeability ratio $(300 \mathrm{mD} / 1700 \mathrm{mD})$ 
MRF became smaller in the interlayered cores with the high permeability ratio (5.7). Nguyen et al. (2005) also confirmed that the interlayer played a negative role in foam performance when there was a strong heterogeneity. It was known that the foam-triggered crossflow usually occurs in heterogeneous cores with capillary communicating (Li et al. 2010; Bertin et al. 1998). The low density allowed the foam in the bottom layer of high permeability to permeate into the top layer of low permeability, while the capillary pressure of the low permeability layer gave rise to the reverse flow to the high permeability layer. Therefore, when the permeability ratio was low, the foam tended to propagate to the low permeability layer decreasing the MRF. However, the existence of interlayer could hinder the foam crossflow creating strong mobility control. Nevertheless, when the permeability ratio was high (i.e., a larger permeability of the high permeability layer), the prevention of downward foam flow by the impermeable interlayer would diminish the foam mobility control.

Based on foam flooding experiments, Li et al. (2010) demonstrated that crossflow was critical in promoting the sweep efficiency of foam flooding. However, we found that when the permeability ratio was high (5.7), the crossflow favored the EOR performance of foam flooding. If the permeability ratio was low (2.3), the crossflow imposed a negative effect on foam flooding (Figs. 12,13). The influence of interlayer on oil recovery was similar to that on mobility control, whereas the positive response of oil recovery to the interlayer seemed less sensitive than that of mobility control, which was related to the distribution of residual oil and the oil de-foaming action.

\subsubsection{Effect of sedimentary rhythm}

In this section, the heterogeneous cores without interlayer were placed in opposite directions to simulate different sedimentary rhythms. The details of foam flooding are given in Table 9.

As shown in Table 9, the reverse rhythm was favorable for waterflooding, whereas the positive rhythm benefited the foam flooding performance. This effect was even more evident at high permeability ratio. During the stage of waterflooding, due to the density difference of oil and water, and the flow resistance difference of high- and lowpermeability layers, the waterline is relatively uniform in the reverse rhythm. A comparison of the two rhythms indicated that the foam was more stable in the high permeability layer because of the low residual oil saturation and was

Table 8 Oil recovery in heterogeneous cores with or without interlayer

\begin{tabular}{llllllll}
\hline Core No. & Interlayer condition & $\begin{array}{l}\text { Permeabil- } \\
\text { ity ratio }\end{array}$ & $\begin{array}{l}\text { Waterflooding } \\
\text { recovery, } \%\end{array}$ & $\begin{array}{l}\text { Foam flooding } \\
\text { recovery, } \%\end{array}$ & $\begin{array}{l}\text { Subsequent water } \\
\text { recovery, } \%\end{array}$ & $\begin{array}{l}\text { Additional oil } \\
\text { recovery, } \%\end{array}$ & $\begin{array}{l}\text { Total recovery, } \% \\
\text { (n) }\end{array}$ \\
\hline 24 & Without interlayer & 2.3 & 32.47 & 11.57 & 16.35 & 27.92 & 60.39 \\
33 & Interlayered & 2.3 & 36.97 & 3.86 & 27.17 & 31.03 & 68.00 \\
27 & Without interlayer & 5.7 & 30.07 & 22.60 & 13.67 & 40.27 & 70.34 \\
34 & Interlayered & 5.7 & 31.36 & 15.01 & 15.67 & 30.68 & 62.40 \\
\hline
\end{tabular}
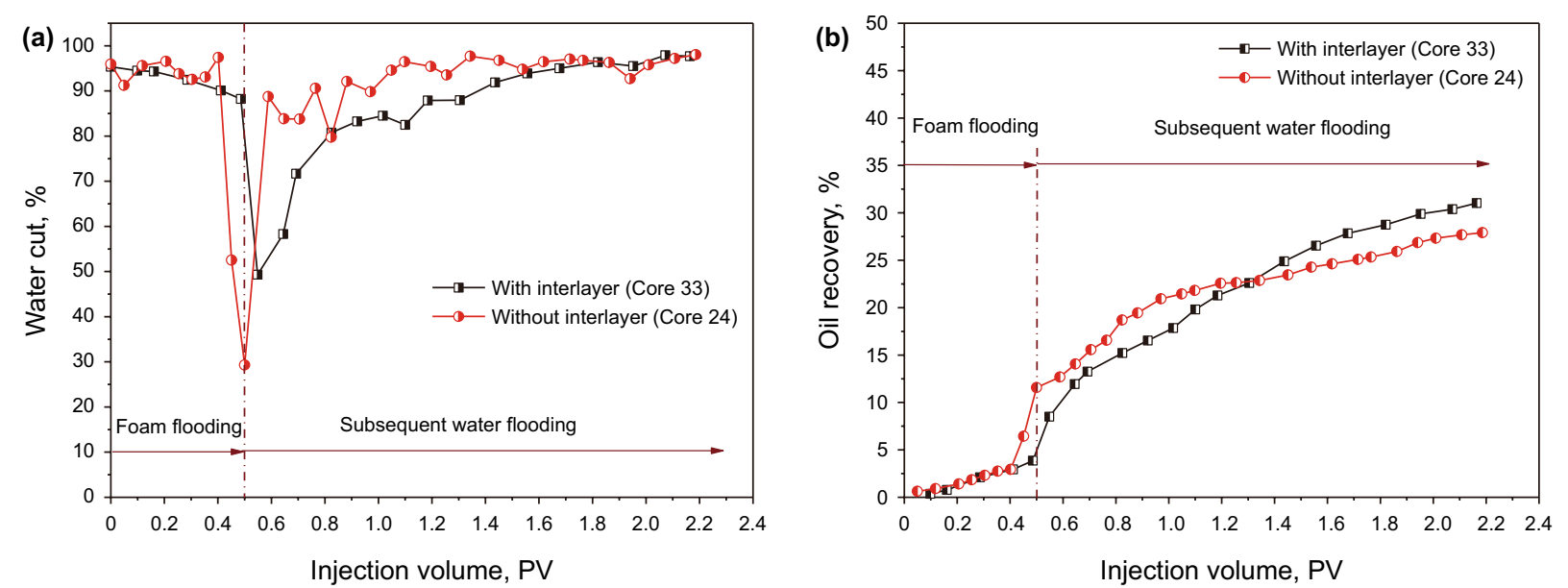

Fig. 12 a Water cut and $\mathbf{b}$ oil recovery as a function of injection volume for cores of a low permeability ratio $(300 \mathrm{mD} / 700 \mathrm{mD}) \mathrm{with}$ or without interlayer 

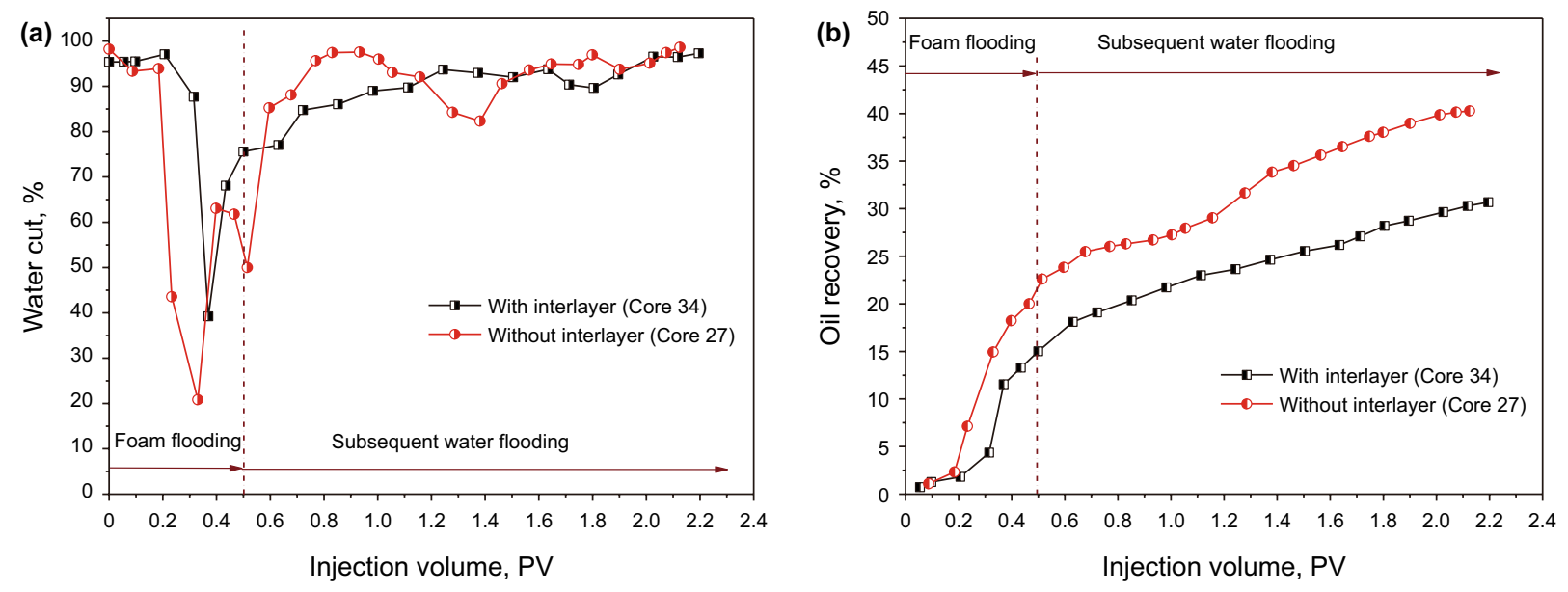

Fig. 13 a Water cut and $\mathbf{b}$ oil recovery as a function of injection volume for cores of a high permeability ratio $(300 \mathrm{mD} / 1700 \mathrm{mD}) \mathrm{with}$ or without interlayer

Table 9 Oil recovery in heterogeneous cores with different sedimentary rhythms

\begin{tabular}{llllllll}
\hline Core No. & Sedimentary rhythm & $\begin{array}{l}\text { Permeabil- } \\
\text { ity ratio }\end{array}$ & $\begin{array}{l}\text { Waterflooding } \\
\text { recovery, } \%\end{array}$ & $\begin{array}{l}\text { Foam flooding } \\
\text { recovery, } \%\end{array}$ & $\begin{array}{l}\text { Subsequent water } \\
\text { recovery, } \%\end{array}$ & $\begin{array}{l}\text { Additional oil } \\
\text { recovery, } \%\end{array}$ & $\begin{array}{c}\text { Total recovery, } \% \\
24\end{array}$ \\
\hline 25 & Positive rhythm & 2.3 & 32.47 & 11.57 & 16.35 & 27.92 & 60.39 \\
27 & Reverse rhythm & 2.3 & 37.27 & 10.75 & 17.06 & 27.81 & 65.08 \\
28 & Positive rhythm & 5.7 & 30.07 & 22.60 & 17.67 & 40.27 & 70.34 \\
\hline
\end{tabular}
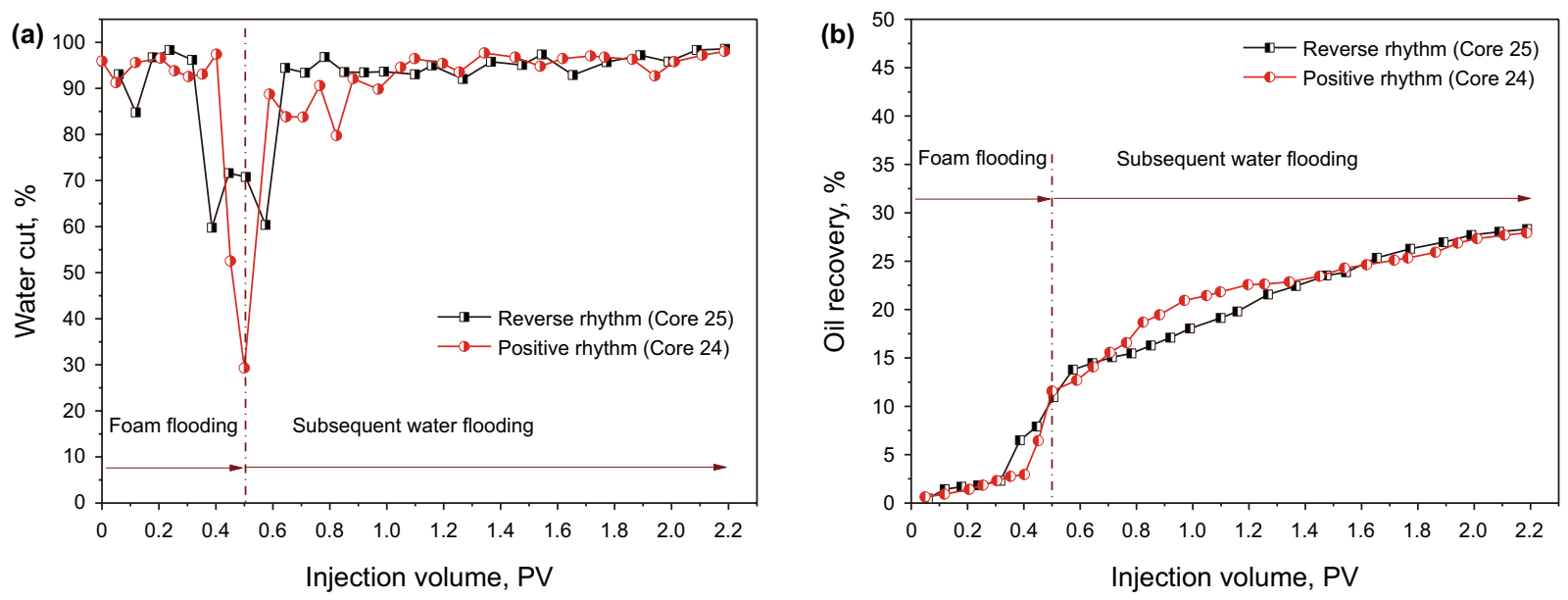

Fig. 14 a Water cut and $\mathbf{b}$ oil recovery as a function of injection volume for cores of a low permeability ratio $(300 \mathrm{mD} / 700 \mathrm{mD}) \mathrm{with}$ different sedimentary rhythms

more abundant in the low permeability layer owing to the gravity segregation, which eventually promoted the efficiency of oil recovery enhancement and water cut reduction under the condition of positive rhythm (Figs. 14, 15).

\subsection{Foam flooding performance in 3D heterogeneous models}

The 3D heterogeneous models were established to 

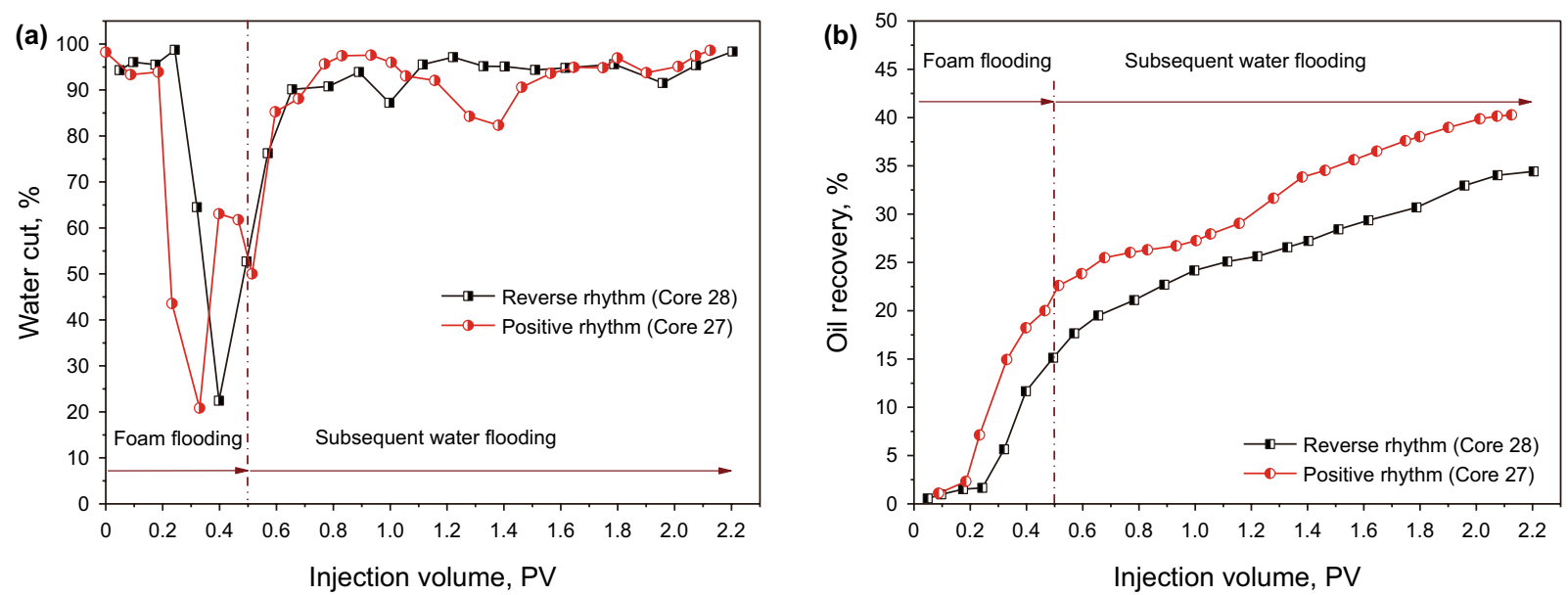

Fig. 15 a Water cut and $\mathbf{b}$ oil recovery as a function of injection volume for cores of a high permeability ratio $(300 \mathrm{mD} / 1700 \mathrm{mD})$ with different sedimentary rhythms

Table 10 Oil recovery in the 3D model

\begin{tabular}{lllllll}
\hline Model No. & $\begin{array}{l}\text { Initial oil satura- } \\
\text { tion, } \%\end{array}$ & $\begin{array}{l}\text { Waterflooding } \\
\text { recovery, } \%\end{array}$ & $\begin{array}{l}\text { Foam flooding } \\
\text { recovery, } \%\end{array}$ & $\begin{array}{l}\text { Subsequent water } \\
\text { recovery, } \%\end{array}$ & $\begin{array}{l}\text { Additional oil } \\
\text { recovery, } \%\end{array}$ & Total recovery, $\%$ \\
\hline A & 72.52 & 42.93 & 7.65 & 6.32 & 13.97 & 56.90 \\
B & 70.06 & 36.60 & 4.65 & 5.90 & 10.83 & 47.53 \\
C & 68.07 & 40.08 & 5.38 & 6.78 & 12.16 & 52.24 \\
\hline
\end{tabular}
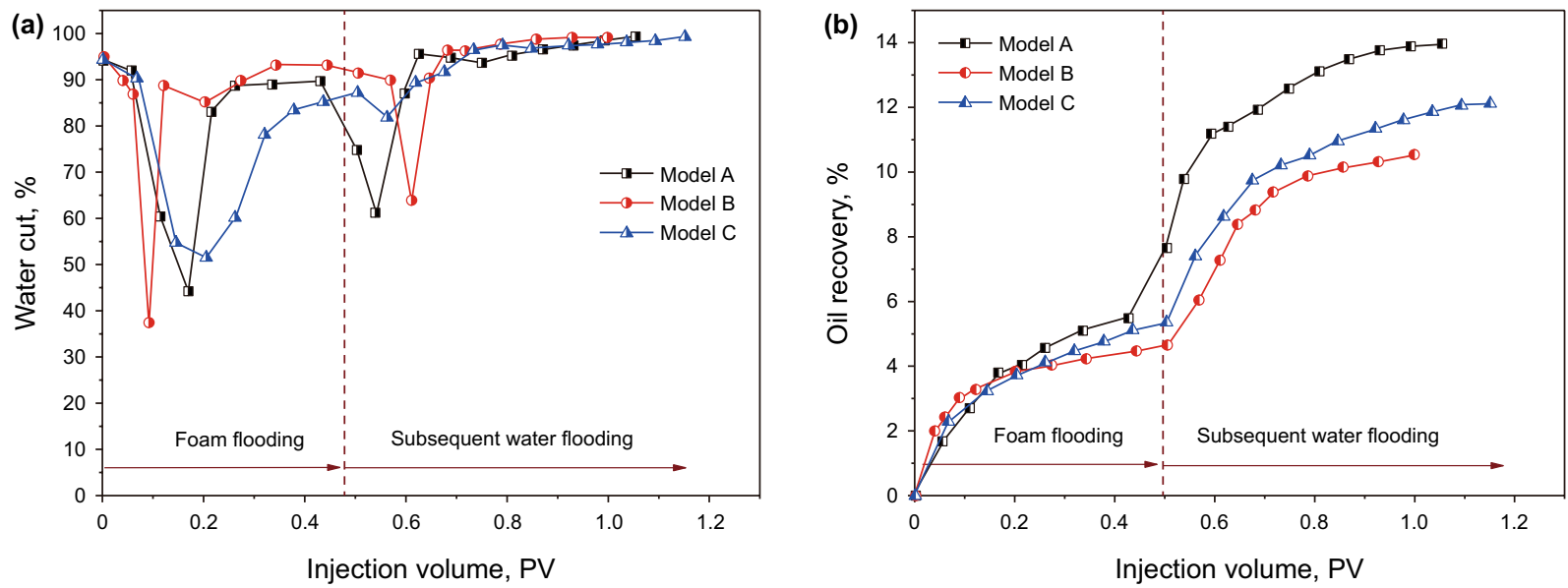

Fig. 16 a Water cut and $\mathbf{b}$ oil recovery as a function of injection volume in 3D heterogeneous models

investigate the effect of areal and vertical heterogeneity on foam flooding performance. The oil recovery data are listed in Table 10. The production details are presented in Figs. 16 and 17.

The experimental results turned out that the maximum waterflooding recovery and additional oil recovery occurred in the model A, which was only vertically heterogeneous (Fig. 16). For the models that were both areally and vertically heterogeneous, when the wells were assigned in the low permeability zone with vertical homogeneity (model C), the oil recovery was found to be higher (Table 10). In order to further analyze foam flooding in the 3D model, we peeled off the sand model layer by layer after foam flooding and carried out image analysis 


\section{(a)}
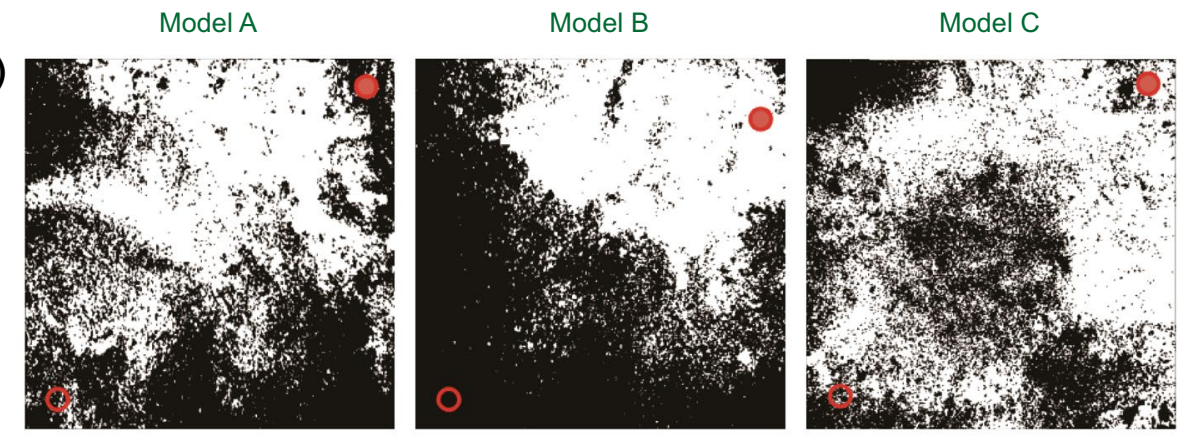

(b)
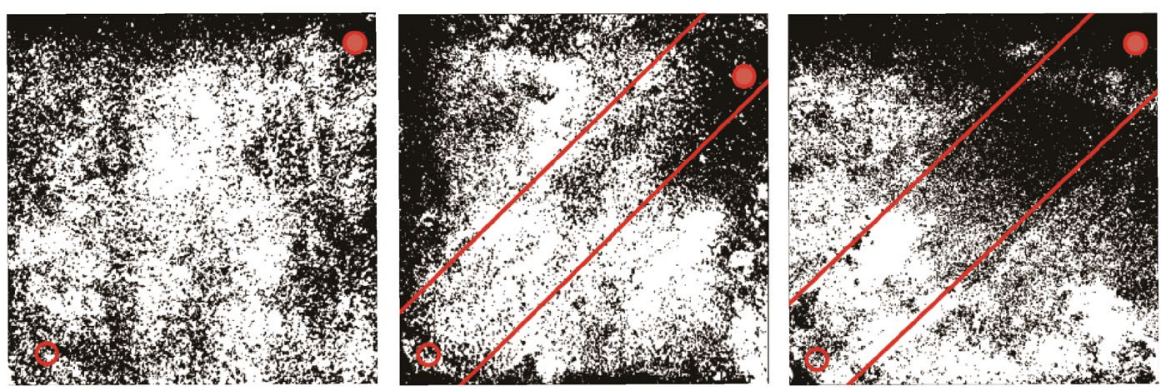

(c)
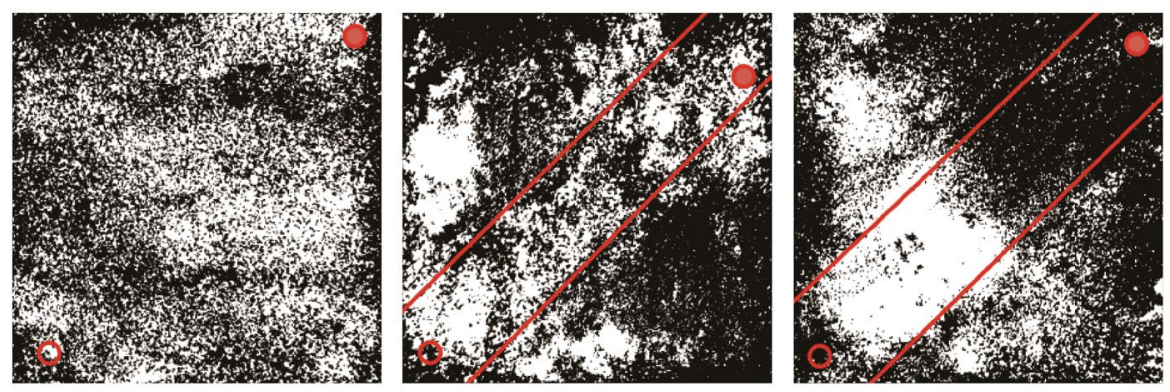

Fig. 17 Distributions of residual oil in different layers of 3D models. a Top, b middle and $\mathbf{c}$ bottom layers. The dark spots represent high oil concentrations, while the lighter spots represent low oil concentrations (open circle: injection well and closed circle: production well)

in terms of each layer. As shown in Fig. 17, uniform swept regions (the light area) were observed in all the middle and bottom layers (Fig. 17b, c), although the residual oil saturation was lower for the less heterogeneous layer. This confirmed that the foam would stabilize the displacement front through improving the mobility control. Meanwhile, a stable displacement and a low residual oil saturation were observed around the production well in the top layer. This interesting phenomenon proved that the gravity segregation of foam took place along the displacement direction, which could be considered as a type of deep fluid diversion. The gravity segregation made a great contribution to oil displacement efficiency in the top layer, but also caused the residual oil mainly distributed in the bottom layer. Therefore, it needs a further research on the optimization of the gravity segregation of foam for achieving a higher sweep efficiency.

\section{Conclusions}

Foam flooding performance in different types of formations was comprehensively investigated to figure out the various EOR mechanisms. Based on the experimental results, some main conclusions can be stated as follows:

1. With an increase in permeability, the mobility control and sequent water seepage resistance of foam were significantly improved. A high flow resistance of foam could be produced in a long distance displacement process, which accordingly resulted in prominent oil recovery efficiency.

2. When foam flooding conducted in the vertical heterogeneous formations, the maximum permeability $K_{\max }$ was mainly responsible for the equilibrium MRF, and the permeability ratio only altered the increasing rate 
of MRF. Meanwhile, the high $K_{\max }$ and large permeability ratio benefited the oil recovery enhancement and water cut reduction. Furthermore, within appropriate permeability ratio range, foam could produce a higher additional oil recovery in a vertical heterogeneous core instead of a homogeneous core.

3. The effect of interlayer on foam flooding varied with permeability ratio. When the permeability ratio was low, the interlayer was favorable for the increase in MRF and oil recovery, while a high permeability ratio did the opposite.

4. In comparison with the reverse rhythm, the positive rhythm was more suitable for foam flooding, especially under a high permeability ratio.

5. Foam was able to tune the areal and vertical heterogeneities through mobility control and gravity segregation, and thus enhanced the oil recovery. However, the effect was not as significant as that in the vertical heterogeneous formations.

Acknowledgements This work was financially supported by the Scientific Research Startup Foundation of Xinjiang University (No. 620312377) and the National Science and Technology Major Project of China (No. 2016ZX05053-013). Special thanks to Sinopec Northwest Company of China for supplying the geological materials and crude oil sample.

Open Access This article is licensed under a Creative Commons Attribution 4.0 International License, which permits use, sharing, adaptation, distribution and reproduction in any medium or format, as long as you give appropriate credit to the original author(s) and the source, provide a link to the Creative Commons licence, and indicate if changes were made. The images or other third party material in this article are included in the article's Creative Commons licence, unless indicated otherwise in a credit line to the material. If material is not included in the article's Creative Commons licence and your intended use is not permitted by statutory regulation or exceeds the permitted use, you will need to obtain permission directly from the copyright holder. To view a copy of this licence, visit http://creativecommons.org/licenses/by/4.0/.

\section{References}

Almajid MM, Kovscek AR. Pore-level mechanics of foam generation and coalescence in the presence of oil. Adv Colloid Interface. 2016;233:65-82. https://doi.org/10.1016/j.cis.2015.10.008.

Arnold SV, Wit K. Rheology of gas/water foam in the quality range relevant to steam foam. SPE J. 1990;5:185-92. https://doi. org/10.2118/18075-PA.

Ashoori E, Marchesin D, Rossen WR. Dynamic foam behavior in the entrance region of a porous medium. Colloid Surfaces A. 2011;377(1):217-27. https://doi.org/10.3997/2214-4609.20145 024.

Bertin HJ, Apaydin OG, Castanier LM, et al. Foam flow in heterogeneous porous media: effect of crossflow. In: SPE/DOE improved oil recovery symposium, 19-22 April, Tulsa, Oklahoma; 1998. https ://doi.org/10.2118/39678-MS.
Blázquez C, Dalmazzone C, Emond E, et al. Crude oil foams. Part 1 -a novel methodology for studying non-aqueous foams formed by depressurization. Fuel. 2016;171:224-37. https://doi. org/10.1016/j.fuel.2015.11.092.

Farajzadeh R, Andrianov A, Zitha PLJ. Investigation of immiscible and miscible foam for enhancing oil recovery. Ind Eng Chem Res. 2009a;49(4):1910-9. https://doi.org/10.1021/ie901109d.

Farajzadeh R, Andrianov A, Bruining $\mathrm{H}$. Comparative study of $\mathrm{CO}_{2}$ and $\mathrm{N}_{2}$ foams in porous media at low and high pressure-temperatures. Ind Eng Chem Res. 2009b;48(9):4542-52. https://doi. org/10.1021/ie801760u.

Farajzadeh R, Andrianov A, Krastev R, Hirasaki GJ, Rossen WR. Foam-oil interaction in porous media: implications for foam assisted enhanced oil recovery. Adv Colloid Interface Sci. 2012;183:1-13. https://doi.org/10.1016/j.cis.2012.07.002.

Hou Q, Li J, Weng R, et al. Recent progress and effects analysis of foam flooding field tests in China. In: SPE enhanced oil recovery conference, 2-4 July, Kuala Lumpur, Malaysia; 2013. https://doi. org/10.2118/165211-MS.

Kamal MS. A review of Gemini surfactants: potential application in enhanced oil recovery. J Surfactants Deterg. 2016;19(2):223-36. https://doi.org/10.1007/s11743-015-1776-5.

Kumar K, Dao EK, Mohanty KK. Atomic force microscopy study of wettability alteration by surfactants. SPE J. 2008;13(02):137-45. https://doi.org/10.2118/93009-PA.

Li RF, Yan W, Liu S, et al. Foam mobility control for surfactant enhanced oil recovery. SPE J. 2010;15(04):928-42. https://doi. org/10.2118/113910-PA.

Li S, Li Z, Li B. Experimental study and application on profile control using high-temperature foam. J Pet Sci Eng. 2011;78(3):567-74. https://doi.org/10.1016/j.petrol.2011.09.002.

Liu R, Liu H, Li X, et al. The reservoir suitability studies of nitrogen foam flooding in Shengli Oilfield. In: SPE Asia Pacific oil and gas conference and exhibition, 20-22 October, Perth, Australia; 2008. https://doi.org/10.2118/114800-MS.

Liu H, Ye P, Li W, et al. Application of nitrogen foam for profile modification in a heterogeneous multi-layer sandstone oilfield. In: SPE Asia Pacific oil and gas conference and exhibition, 18-20 October, Brisbane, Queensland, Australia; 2010. https://doi. org/10.2118/130767-MS.

Liu H, Hou J, Wu G, et al. Oil recovery for heavy oil by displacing agent/foam assisted steam flooding: laboratory experiments, numerical simulations and field performances. In: SPE international heavy oil conference and exhibition, 8-10 December, Mangaf, Kuwait; 2014. https://doi.org/10.2118/172861-MS.

Ma K, Jia X, Yang J, et al. Nitrogen foam flooding pilot test for controlling water cut and enhance oil recovery in conventional heavy oil reservoirs of china offshore oilfield. In: SPE Asia Pacific oil and gas conference and exhibition, 22-24 October, Jakarta, Indonesia; 2013. https://doi.org/10.2118/165808-MS.

Nguyen QP, Currie PK, Zitha PLJ. Effect of crossflow on foam-induced diversion in layered formations. SPE J. 2005;10(01):54-65. https ://doi.org/10.2118/82270-PA.

Pang Z, Lyu X, Zhang F, et al. The macroscopic and microscopic analysis on the performance of steam foams during thermal recovery in heavy oil reservoirs. Fuel. 2018;233:166-76. https://doi. org/10.1016/j.fuel.2018.06.048.

Parlar M, Parris MD, Jasinski RJ. An experimental study of foam flow through Berea sandstone with applications to foam diversion in matrix acidizing. In: SPE western regional meeting, 8-10 March, Bakersfield, California; 1995. https://doi.org/10.2118/29678-MS.

$\mathrm{Pu} \mathrm{W}$, Yuan $\mathrm{C}, \mathrm{Hu} \mathrm{W}$, et al. Effects of interfacial tension and emulsification on displacement efficiency in dilute surfactant flooding. RSC Adv. 2016;6(56):50640-9. https://doi.org/10.1039/C6RA0 $6027 \mathrm{G}$. 
$\mathrm{Pu}$ W, Wei P, Sun L, Wang S. Stability, $\mathrm{CO}_{2}$ sensitivity, oil tolerance and displacement efficiency of polymer enhanced foam. RSC Adv. 2017;7(11):6251-8. https://doi.org/10.1039/C6RA27063H.

Shamekhi H, Kantzas A, Bryan JL, et al. Insights into heavy oil recovery by surfactant, polymer and ASP flooding. In: SPE heavy oil conference-Canada, 11-13 June, Calgary, Alberta, Canada; 2013. https://doi.org/10.2118/165440-MS.

Shokrollahi A, Ghazanfari MH, Badakhshan A. Application of foam floods for enhancing heavy oil recovery through stability analysis and core flood experiments. Can J Chem Eng. 2014;92(11):197587. https://doi.org/10.1002/cjce.22044.

Siddiqui S, Talabani S, Yang J, Saleh S, Islam MR. An experimental investigation of the diversion characteristics of foam in berea sandstone cores of contrasting permeabilities. In: SPE production operations symposium, 9-11 March, Oklahoma City, Oklahoma; 1997. https://doi.org/10.2118/37463-MS.

Sun Q, Li Z, Li S, et al. Utilization of surfactant-stabilized foam for enhanced oil recovery by adding nanoparticles. Energy Fuel. 2014;28(4):2384-94. https://doi.org/10.1021/ef402453b.

Thompson K, Gdanski RD. Laboratory study provides guidelines for diverting acid with foam. SPE Prod Facil. 1993;8(04):285-90. https://doi.org/10.2118/23436-PA.

Vernáez O, García A, Castillo F, et al. Oil-based self-degradable gels as diverting agents for oil well operations. J Pet Sci Eng. 2016;146:874-82. https://doi.org/10.1016/j.petrol.2016.07.029.
Wang J, Liu H, Ning Z. Experimental research and quantitative characterization of nitrogen foam blocking characteristics. Energy Fuel. 2012;26(8):5152-63. https://doi.org/10.1021/ef300939j.

Wang D, Hou Q, Luo Y, et al. Feasibility studies on $\mathrm{CO}_{2}$ foam flooding EOR technique after polymer flooding for Daqing Reservoirs. J Dispers Sci Technol. 2015;36(4):453-61. https://doi. org/10.1080/01932691.2014.880846.

Wei P, Pu WF, Sun L, Pu Y, Li D. Role of water-soluble polymer on foam-injection process for enhancing oil recovery. J Ind Eng Chem. 2018;65:280-9. https://doi.org/10.1016/j.jiec.2018.04.039.

Xiao K, Jiang H, Wang Q, et al. Adaptability study on plugging thief zones with asphalt particle in polymer flooding offshore field. In: SPE energy resources conference, 9-11 June, Port of Spain, Trinidad and Tobago; 2014. https://doi.org/10.2118/169931-MS.

Zhang Y, Yue X, Dong J, et al. New and effective foam flooding to recover oil in heterogeneous reservoir. In: SPE/DOE improved oil recovery symposium, 3-5 April, Tulsa, Oklahoma; 2010. https:// doi.org/10.2118/59367-MS.

Zhao L, Li A, Chen K. Development and evaluation of foam agents for high salinity tolerance. J Pet Sci Eng. 2012;81:18-23. https://doi. org/10.1016/j.petrol.2011.11.006. 